IRA-International Journal of Applied Sciences ISSN 2455-4499; Vol.06, Issue 02 (2017)

Institute of Research Advances

Pg. no. 31-33

https://research-advances.org/index.php/IRAJAS

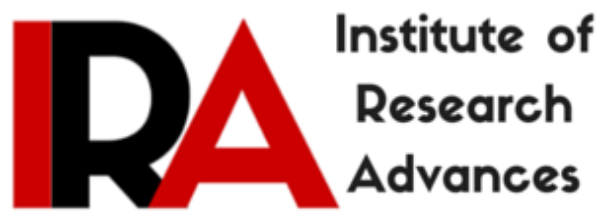

\title{
Efficient Synthesis and Characterization of 4- (1, 3-Dioxoisoindolin-2yl) Benzaldehyde
}

\author{
Sharad S. Sankhe ${ }^{1}$, Nitesh R. Chindarkar ${ }^{2}$ \\ ${ }_{1,2}$ Organic Research Laboratory, Patkar-Varde College of Science, \\ Goregaon (West), Mumbai 400062, India.
}

Type of Review: Peer Reviewed.

DOI: http://dx.doi.org/10.21013/jas.v6.n2.p1

\section{How to cite this paper:}

Sankhe, S., \& Chindarkar, N. (2017). Efficient Synthesis and Characterization of 4- (1, 3-Dioxoisoindolin-2yl) Benzaldehyde. IRA-International Journal of Applied Sciences (ISSN 2455-4499), 6(2), 31-33. doi:http://dx.doi.org/10.21013/jas.v6.n2.p1

(C) Institute of Research Advances

\section{(cc) EY-NC}

This work is licensed under a Creative Commons Attribution-Non Commercial 4.0 International License subject to proper citation to the publication source of the work.

Disclaimer: The scholarly papers as reviewed and published by the Institute of Research Advances (IRA) are the views and opinions of their respective authors and are not the views or opinions of the IRA. The IRA disclaims of any harm or loss caused due to the published content to any party. 


\begin{abstract}
The titled 4-(1,3-dioxo-2,3-dihydro-1H-inden-2-yl)benzaldehyde has been synthesized from phthalic anhydride and p-toluidene followed by use of $\mathrm{H}_{2} \mathrm{O}_{2}$ in ethanol. Compounds characterized on the basis of $1 H-N M R$.
\end{abstract}

Keywords: Phthalic anhydride and $\mathrm{H}_{2} \mathrm{O}_{2}$ in ethanol

\title{
I. INTRODUCTION
}

Benzaldehyde1-3 $\left(\mathrm{C}_{6} \mathrm{H}_{5} \mathrm{CHO}\right)$ is a chemical compound consisting of a benzene ring with an aldehyde substituent. It is the simplest representative of the aromatic aldehydes and one of the most industrially used members of this family of compounds.It is commonly employed as a commercial food flavourant or industrial solvent, benzaldehyde is used chiefly in the synthesis of other organic compounds, ranging from pharmaceuticals to plastic additives.

\section{EXPERIMENTAL}

The uncorrected M.P. Of compounds were taken in an open capillary in a paraffin bathcand compared with those in the literature values. 1H-NMR and 13C-NMR were recorded on a $300 \mathrm{MHz}$ spectrometer in DMSO solvent.

\section{RESULTS AND DISCUSSION}

\section{Synthesis of 2-(p-tolyl)isoindoline-1,3-dione (a)}

To phthalic anhydride $(1 \mathrm{mmol})$ and p-toluidine which were refluxed in glacial acetic acid for $3 \mathrm{hrs}$. The progress of the reaction was monitored using TLC. This reaction was then quenched in water. The crude product was filtered and washed several times with water and then dried, $\mathrm{mp} 180-185^{\circ} \mathrm{C}$ and $84 \%$ yield. $1 \mathrm{H}-\mathrm{NMR}$ (DMSO) $\delta$-3.251(s, 3H), $\delta$-7.281-7.935 (m, 8H, Ph). 13C-NMR $\delta-21,123$, 126, 129, 129, 131, 134, 137, 167.

\section{Synthesis of 2-(4-(bromomethyl) phenyl) isoindoline-1,3-dione (b)}

The product obtained in the first step is then subjected to bromination by using NBS in presence of benzoyl-peroxide as catalyst in $\mathrm{CCl}_{4}$. The reaction mixture is refluxed for $2 \mathrm{hrs}$ and it is monitored by TLC. The reaction product found as a white mass. The mixture was brought to room temperature, and $\mathrm{CCl}_{4}$ was then evaporated, filtered and washed with $\mathrm{CCl}_{4}$ and water successively. The crude product was then dried for 2 hours. The dried product, mp $198-200^{\circ} \mathrm{C}$, was not dissolving even in methanol so we could not able to predict the compound using NMR spectroscopic technique. However compound gave positive Bleistein's test which confirmed the presence of bromine.

\section{Synthesis of 4-(1,3-dioxoisoindolin-2-yl) benzaldehyde (c)}

The brominated product (b) was then oxidised to benzaldehyde by use of $\mathrm{H}_{2} \mathrm{O}_{2}$ in ethanol as oxidant ${ }^{5}$ at reflux in $3 \mathrm{~h}$. In other solvents, such as tetrahedron, chloroform, and methylene chloride, much longer time was and the conversion was poorer required.

The ethanol is then evaporated and dried for $2 \mathrm{hrs}$ in an hot air oven. 1H NMR (DMSO) $\delta-10.068$ (s, 1H), $\delta$-7.388-7.839 (m, 8H, Ph). 13C-NMR $\delta$-123, 130, 134, 135, 166, 167,191. 
<smiles>Cc1ccc(N2C(=O)c3ccccc3C2=O)cc1</smiles>

(a)<smiles>Cc1ccc(N2C(=O)c3ccccc3C2=O)cc1</smiles>

(a)<smiles>C[14CH2][14CH2][14CH2]Br</smiles>

(b)

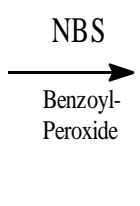

$\underset{\text { Ethanol }}{\stackrel{\mathrm{H}_{2} \mathrm{O}_{2}}{\longrightarrow}}$

(c)<smiles>O=Cc1ccc(N2C(=O)c3ccccc3C2=O)cc1</smiles>

SCHEME 1

\section{Acknowledgment}

Authors thanks to Rajesh Kenny, Suyog Marathe, Jitendra Patil, S.S. \& L.S. Patkar College and A. P. Shah Institute of Technology, Thane, for support.

\section{References}

[1] Hass H. B.; Bender, M.L. Am. Chem.Soc (1949), 71, 1767-1769

[2] Frazen, V.Org, Synth, (1973), 5, 872-874

[3] Jun Matsui, Ian A. Nicholls, Isao Karube, and Klaus Mosbach, J. Org. Chem.,16, (1996) pp 5414-5417

[4] Kiyoshi Tanemura,Tsuneo Suzuki,Yoko Nishida,Koko Satsumabayashi,Takaaki Horaguchi, (2003), 32, No.10

[5] Jingting Tang, Jinlong Zhu, Zongxuan Shen ande Yawen Zhang, Tetrahedron Letters 48 (2007) 1919-1921 